Proc. Indian Acad. Sci., Vol. 86 A, No. 5, November 1977, pp. 465-470, () Printed in India.

\title{
Molecular complexes of macrocyclic polyethers with 1, 3, 5-trinitrobenzene
}

\author{
Y JAYATHIRTHA and V KRISHNAN \\ Department of Inorganic and Physical Chemistry, Indian Institute of Science, \\ Bangalore 560012 \\ MS received 30 July 1977
}

\begin{abstract}
The interaction of six macrocyclic polyethers with 1, 3, 5-trinitrobenzene has been studied by spectroscopic methods. The association constants have been evaluated by 'HMR chemical shift method. There is evidence that major contribution to the interaction is via $n$ and $\pi$ electrons. The donor strengths of the polyethers have been evaluated.
\end{abstract}

Keywords. Molecular complexes; macrocyclic polyethers; association constants; 'HMR chemical shifts; donor strengths.

\section{Introduction}

Macrocyclic polyethers synthesised by Pedersen (1967) have been the subject of much study due to their ability to solubilize alkali and alkaline earth metal ions in organic solvents (Pedersen and Frensdorf 1972) and their close resemblance to naturally occurring antibiotics (Szabo et al 1973). As model systems for peptide antibiotics, their complexation behaviour with alkali and alkaline earth metal ions has been well studied (Christiansen et al 1974; Truter 1973). However, very little attention has been paid to their ability to form molecular complexes. This would be particularly relevant to the study of these ethers as model systems for antibiotics, since interaction with the membrane would precede the complexation and this interaction is very likely to be of electron donor-acceptor type. It would then be of interest to study whether the polyethers which exhibit permselective conductance behaviour in the membrane, would form molecular complexes and the nature of stabilisation forces responsible for the formation of such complexes. Goldberg (1975) has shown from x-ray structural studies that hydrogen bonding and geometric factors form the stabilisation forces in the molecular complexes of two polyethers. No information is available about their stabilities and structures in solution which would have been useful in assessing the nature of binding sites and conformations of ethers in solution.

We have examined here the ability of six macrocyclic polythers (figure 1) to form molecular complexes with 1, 3, 5-trinitrobenzene (TNB) in chlorinated hydrocarbons.

\section{Experimental}

The I.U.P.A.C. nomenclature and the widely used names of these polyethers are: 2, 3-benzo-1, 4, 7, 10, 13-pentaoxacyclopentadeca-2-ene, benzo-15-Crown-5, (I); 


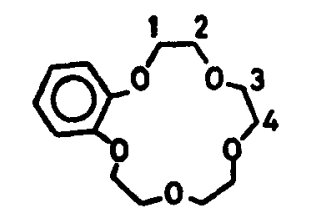

Benzo-15-crown-5

I

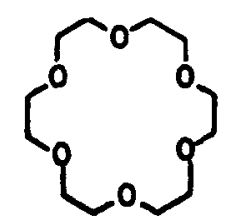

18-crowñ-6

IV

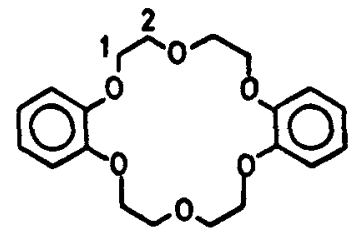

Oibenzo-18-crown-6

II

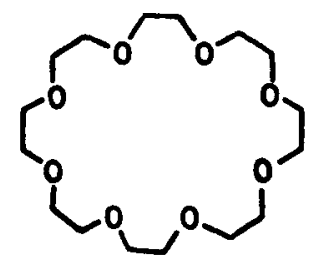

24-crown-6

$\checkmark$

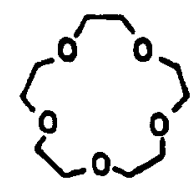

15-crown-5

III

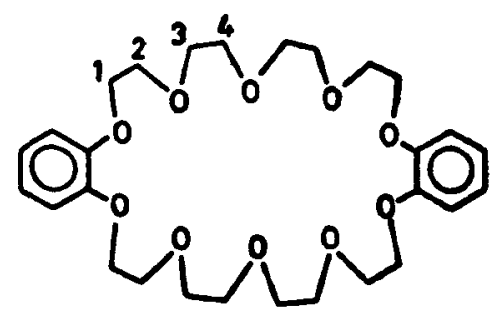

Dibenzo-30-crown -10

VI

Figure 1. Structural formulas for macrocyclic polyethers

2, 3, 11, 12-dibenzo-1, 4, 7, 10, 13, 16-hexaoxacyclooctadeca-2, 11-diene, dibenzo-18Crown-6, (II); 1, 4, 7, 10, 13-pentaoxacyclopentane, 15-Crown-5, (III); 1, 4, 7, 10, 13, 16-hexaoxacyclooctadecane, 18-Crown-6, (IV); 1, 4, 7, 10, 13, 16, 19, 22-octaoxacyclotetracosane, 24-Crown-8, (V); 2, 3, 17, 18-dibenzo-1, 4, 7, 10, 13, 16, 19, 22, 25, 28-decaoxacyclotriaconta-2, 17-diene, dibenzo-30-Crown-10, (VI). The ethers were synthesised and purified according to published procedures (Pedersen 1967; Dale and Kristiansen 1972; Cook et al; Gokel et al 1974). 1, 3, 5-trinitrobenzene (TNB) was obtained from BDH and twice crystallised from benzene. All the solvents used were of spectroscopic grade.

The 'HMR measurements were carried out on a Varian HA 100 NMR spectrometer using $\mathrm{C}^{2} \mathrm{HCl}_{3}$ and $\mathrm{C}_{2} \mathrm{H}_{4} \mathrm{Cl}_{2}$ as solvents with TMS as internal standard. The electronic absorption spectra were recorded on a Unicam SP700A spectrophotometer with $\mathrm{CH}_{2} \mathrm{Cl}_{2}$ as solvent. The infrared spectra were taken on a Carl Zeiss UR 10 spectrometer using $\mathrm{KBr}$ and $\mathrm{KRS}$ cells.

The association constants have been evaluated by 'HMR shift method as described in the literature (Foster and Fyfe 1965). The ether (I)-TNB complexation was followed under the condition (ether) $)_{0}$, (donor) $>$ (TNB), (acceptor), and phenyl signal of TNB $(0.06 \mathrm{M})$ at $958 \mathrm{~Hz}$ was monitored in $\mathrm{C}^{2} \mathrm{HCl}_{3}$ solutions containing large excess of ether (0.9-5.5 M). In the case of other ethers (II) and (VI) owing to the poor solubility of these ethers in $\mathrm{C}^{2} \mathrm{HCl}_{3}, \mathrm{C}_{2} \mathrm{H}_{4} \mathrm{Cl}_{2}$ was used as a solvent under the condition (acceptor) $)_{0}>$ (donor) $)_{0}$. The shifts in phenyl signals of these ethers $(0.02 \mathrm{M})$ were monitored in solutions containing excess of TNB $(0.2-1 \cdot 7 \mathrm{M})$. These shifts were analysed graphically and by computation to calculate the association constants $\mathrm{K}$ and $\triangle_{0}$, the chemical shift of TNB or phenyl protons signals of the ethers in the complex relative to the shift in pure components. MINDS programme was used for computation work (Dodson et al 1971). The values of $K$ and $\Delta_{0}$ obtained from graphical method compares favourably with the computed values. The 


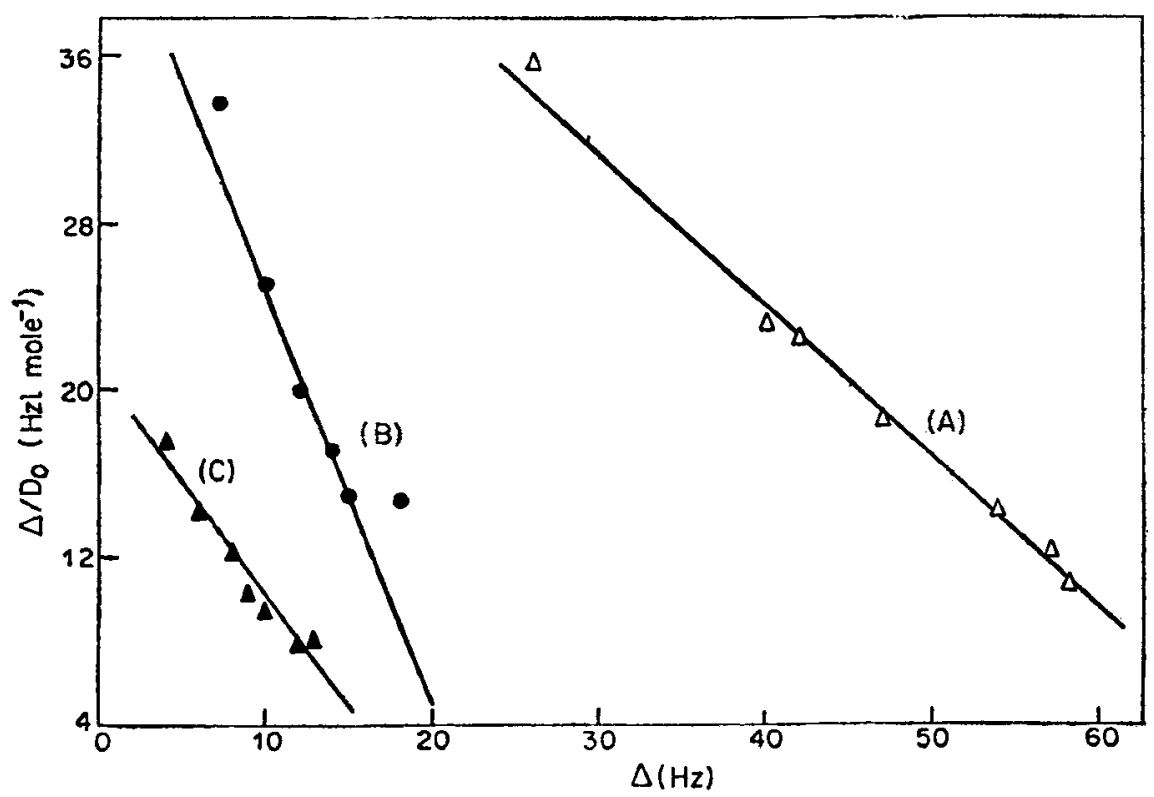

Figure 2. Plots of $\Delta / D_{0}$ against $\Delta$ for the complexes of TNB with $A$. Benzo-15crown-5; B. Dibenzo-30-crown-10 and C. Dibenzo-18-crown-6 at $31 \cdot 5^{\circ} \mathrm{C}$.

linearity of the plots (figure 2) suggests a $1: 1$ complexation of ethers with TNB. It was found possible to carry out temperature dependance studies at two temperatures for two ethers only due to the limited solubility of the ethers in solvents used.

The charge transfer maxima of the complexes $(1: 1), v_{\mathrm{CT}}$, were measured according to the method of Krishna and Bhowmick (1968) since the charge transfer absorptions lie beneath the absorptions of TNB. The ionisation of the donor ethers $\left(I^{D}\right)$ were calculated using the relationship

$$
h \nu_{\mathrm{CT}}=a I^{D}+b
$$

The values of $a$ and $b$ are taken from Foster (1959). The results are given in table 2 .

\section{Results and discussion}

The 'HMR resonances of the polyethers and their assignments are given in table 1 . The 'HMR spectrum of benzene substituted ether (I) yield valuable information due to ring current magnetic anisotropy and this led to spatial relationship of ether protons and aromatic group. The $100 \mathrm{MHZ}$ 'HMR spectra of benzene substituted ethers, (D), (II) and (VI), though not well resolved in the phenyl signals (singlets are observed), the ether protons signals show multiplets. It has been found possible to identify two multiplets $\left(A A^{\prime} B B^{\prime}\right)$ arising from each of the $1,1^{\prime}$ and $2,2^{\prime}$ protons in ethers (I) and (VI) while these are not well resolved in ether (II) (only a doublet is observed). These assignments agree well with the work of Live and Chan (1976). The nonbenzenoid ether proton resonances occur as singlets and yield very little information concerning the protons environments. The data presented in table 2 
Table 1. 'HMR spectral data of macrocyclic polyethers and their assignments.

\begin{tabular}{lcc}
\hline Ether & $(\mathrm{Hz})$ in $\mathrm{C}^{9} \mathrm{HCl}_{\mathbf{3}}$ & assignments \\
\hline Benzo-15-Crown-5, (I) & 374 & 3,4 \\
& 394 & $2,2^{\prime}$ \\
& 408 & $1,1^{\prime}$ \\
& 686 & aryl \\
Dibenzo-18-Crown-6 (II) & 414 & $1,1^{\prime}$ \\
& 420 & $2,2^{\prime}$ \\
& 696 & aryl \\
15-Crown-5, (III) & 366 & ether \\
18-Crown-6, (IV) & 356 & ether \\
24-Crown-8, (V) & 360 & ether \\
Dibenzo-30-Crown-10, (VI) & 376,378 & 3,4 \\
& 393 & $2,2^{\prime}$ \\
& 420 & $1,1^{\prime}$ \\
& 694 & aryl \\
\hline
\end{tabular}

Table 2. Measured properties of macrocyclic polyether-TNB interaction

\begin{tabular}{ccccc}
\hline Donor ether & $\begin{array}{c}\text { Association constant } \\
\left(1 \text { mole }^{-1}\right)\end{array}$ & $\Delta_{0}(\mathrm{~Hz})$ & $\nu_{\mathrm{Cr}}\left(\mathrm{cm}^{-1}\right)$ & $I^{D}(\mathrm{ev})$ \\
\hline I & $\begin{array}{c}0.632 \dagger \\
0.514 \ddagger\end{array}$ & 77 & 25,320 & 8.29 \\
II & $1.091 \dagger$ & 19 & 23,530 & 8.05 \\
III & - & - & 23,225 & 8.01 \\
IV & - & - & 25,640 & 8.34 \\
V & - & - & 23,810 & 8.09 \\
VI & $2.000 \dagger$ & 22 & 22,990 & 7.98 \\
\hline
\end{tabular}

fat $31^{\circ} 5^{\circ}$ tat $50^{\circ} *$ at $45^{\circ}$

have been helpful in arriving at the possible geometry of the molecular complexes in solution (vide infra).

The low values of association constants suggest weak interaction of the ethers with TNB. Lack of data on the nonbenzenoid ethers is due to small shifts of the TNB signals on addition of large excess of ethers and these could not be monitored with sufficient accuracy. However, the fact that they form molecular complexes is shown by the appearance of charge transfer absorptions. The magnitudes of association constants obtained in the present study show that larger cyclic ether (VI) forms a stabler complex in solution, relative to the ethers (I) and (II). The limited temperature dependance studies of association constants in the ethers (I) and (VI) permit us to compare the thermodynamic parameters. Thus at $304.6^{\circ}$ the $\Delta F^{\prime}, \Delta H^{\theta}$ and $T \triangle S$ values of ether (I) and ether (VI) are $1.16 \mathrm{~kJ} / \mathrm{mol},-12 \cdot 10 \mathrm{~kJ} / \mathrm{mol}$ and $-13 \cdot 24$ $\mathrm{kJ} / \mathrm{mol}$ and $-1.75 \mathrm{~kJ} / \mathrm{mol},-20.43 \mathrm{~kJ} / \mathrm{mol}$ and $-18.66 \mathrm{~kJ} / \mathrm{mol}$ respectively. The 
magnitude of enthalpy and entropy of complexation of ether (VI) relative to those of ether (I) suggests that increased size of the ether and presence of an additional benzene ring favours better complexation.

Attempts to isolate the molecular complexes in crystalline state have so far been unsuccessful except in the case of ether (D-TNB. The HMR spectrum of the isolated complex in $\mathrm{C}^{2} \mathrm{HCl}_{3}$ is very similar to the spectrum obtained from a solution containing equimolar concentration of ether (I) and TNB. This permits us to compare the proton resonances of other ethers in the $1: 1$ solutions containing TNB. It is observed that the phenyl protons of TNB and of the ethers (I), (II) and (VI) occur in a shielded region. Further, the 2 and $2^{\prime}$ protons of these ethers are similarly shielded as a result of complexation. This suggests that TNB is situated predominantly over the phenyl ring of the ether at a distance away from the mutual deshielding zones of the two rings. Construction of CPK molecular models for the complexes showed that such an arrangement would lead one of the nitro groups of TNB projected over the cavity and in proximity to one of each of the $2,2^{\prime}$-protons. This leads to preferential shielding of these protons. It is suggested that in the case of nonbenzenoid ethers, the TNB is situated over the cavity. The $\mathrm{CH}_{2}-\mathrm{O}-\mathrm{CH}_{2}$-signal in these ethers do not change appreciably $(1-2 \mathrm{~Hz})$ when compared to benzene substituted ethers $(5-8$ $\mathrm{Hz}$ ). The possibility of cage structures for these molecular complexes is ruled out since molecular dimensions of these ethers do not permit this.

The infrared spectra of the complexes, $1: 1$ solid mixtures were compared with the vibrations of the individual components. It is found that vibrations in the region $1300-1200 \mathrm{~cm}^{-1}$ arising from the $\mathrm{CH}_{2}-\mathrm{O}-\mathrm{CH}_{2}$ groups of the ethers are shifted to higher frequencies while the band at $640 \mathrm{~cm}^{-1}$ of TNB is shifted in lower frequencies in the complexes. The latter band has been assigned to $\delta \mathrm{NO}_{2}$ of TNB. The lowering of this band has been attributed to the decreased bending force constant as a consequence of reduced $\pi$-bond order of the $\mathrm{NO}_{2}$ group of TNB resulting from the charge donation to $\pi^{*}$ orbital. It is difficult to identify this effect in the $\mathrm{NO}_{2}$ stretching frequency due to overlapping of $-\mathrm{CH}_{2}-\mathrm{O}-\mathrm{CH}_{2}-$ vibrations. The band at $980 \mathrm{~cm}^{-1}$ of the pure ether (I) is absent in the isolated complex. This band has been assigned as complex sensitive band since the band is absent in the complexes (Poonia 1974). We assign this band as conformation sensitive band arising from the $\mathrm{CH}_{2}$ rocking vibration of a gauche $\mathrm{O}-\mathrm{CH}_{2}-\mathrm{O}$ group similar to that ethylene glycols (Miyake 1960). The absence of this band in the complex is attributed to a conformer of the ether (I) in which the $\mathrm{O}-\mathrm{CH}_{2}-\mathrm{CH}_{2}-\mathrm{O}$ group is in trans configuration. In the complexes of other ethers the presence of a band in this region suggests a gauche configuration of the $\mathrm{O}-\mathrm{CH}_{2}-\mathrm{CH}_{2}-\mathrm{O}$ group.

The donor strengths of these ethers expressed as ionization potentials (table 2) do not show significant variation in going from benzene substituted ethers to simple ones. The smallness of $\triangle_{0}$ values and their app 2 rent independence of donor strengths suggest that the ring current effects may form the stabilisation force in these complexes. Since the ethers possess both increvalent $n$ sites (lone pair electrons of ether oxygens) and $\pi$ sites, the molecular complexes formed can be classified as sacrificial $\pi \cdot \pi$ type, in the case of (I), (II) and (VI) and $n-\pi$ type in the case of (III), (IV) and (V). The latter type of complexation gains support from the observation that fluoranil $(\pi-$ acceptor) forms complexes with (III) (IV) and (V) (unpublished). The data presented here affords the first example of molecular complexation of macrocyclic polyethers with $\pi$-acceptors. 


\section{Acknowledgements}

The authors are thankful to $R$ Foster of the University of Dundee for many fruitful discussions and $\mathrm{J} A$ Chaudek for the computer programme. One of the authors (YJ) is thankful to NCERT, New Delhi, for the financial support.

\section{References}

Christiansen J J, Eatough D J and Izatt R M 1974 Chem. Rev. 74351

Cook F L et al 1974 Tetrahedron Lett. 4029

Dale J and Kristiansen P O 1972 Acta Chim. Scand. 261471

Dodson B et at $1971 \mathrm{~J}$. Chem. Soc. 1283

Foster R 1959 Nature (London) 1831253

Foster R and Fyfe C A 1965 Trans. Faraday Soc. 611626

Goldberg I 1975 Acta. Cryst. B31 754, 2592

Gokel G W et al 1974 J. Org. Chem. 392445

Krishna V G and Bhowmick B B 1968 J. Am. Chem. Soc. 901700

Live D and Chan S I 1976 J. Am. Chem. Soc. 983769

Miyake A $1960 \mathrm{~J}$. Am. Chem. Soc. 823040

Pedersen C J 1967 J. Am. Chem. Soc. 897017

Pedersen C J and Frensdorf H K 1972 Angew. Chem. Int. Ed. Engl. 1116

Poonia N S 1974 J. Am. Chem. Soc. 961012

Szabo C et al 1973 Membranes Vol. 2179

Truter M R 1973 Struct. Bonding (Berlin) 1672 